
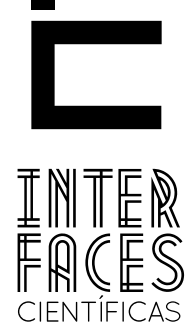

DIREITO

\title{
BERNARDO PEREIRA DE VASCONCELOS: REALPOLLTIK E DEFESA DAS GARANTIAS E LIBERDADES INDIVIDUAIS NO BRASIL IMPERIAL
}

Hélio das Chagas Leitão Neto ${ }^{1}$

\section{RESUMO}

Bernardo Pereira de Vasconcelos foi um estadista da época do Império no Brasil, contribuído para o nascimento de nossas primeiras instituições, além de ter sido um defensor dos direitos fundamentais concernentes à liberdade. Apesar de monarquista e escravagista, sempre foi um crítico de seu tempo e precursor no Brasil da previsão normativa do princípio do devido processo legal e do juiz natural, tendo sido um dos líderes do movimento de 1831, que culminou com a deposição de Dom Pedro I. Sua inteligência e pragmatismo político foi observada por José Murilo de Carvalho, como um praticante da realpolitik.

\section{PALAVRAS-CHAVE}

Política. História. Brasil Império. Monarquia. Realpolitik. Conservadorismo. Escravidão. Direitos Fundamentais. Garantias. Devido Processo Legal. Juiz Natural.

\section{ABSTRACT}

Bernardo Pereira de Vasconcelos was a statesman of the era of the Empire in Brazil, and contributed to the birth of our first institutions, besides being a predecessor of fundamental rights pertaining to freedom. Although he was an adeptor of slavery and monarchy, he has always been a critic of his time in Brazil, and the precursor of the prediction rules of the principle of due process and natural judge, having been one of the leaders of the movement of 1831, which culminated with the deposition of Dom Pedro I. His intelligence and political pragmatism was observed by José Murilo de Carvalho, as a practitioner of realpolitik.

\section{KEYWORDS}

Politics. History. Brazil Empire. Monarchy. Realpolitik. Conservatism. Slavery. Fundamental Rights . Warranties . Due Process of Law . Judge Natural. 


\section{RESUMEN}

Bernardo Pereira de Vasconcelos fue un estadista de la época Império brasileña, Brasil, que ha contribuído para El surgimento de nuestras primeras instituciones, además de tener acutado en la defensia de lós derechos fundamentales referentes a libertad. Aunque fue monárquico y apoyar la esclavitud, siempre ha sido um crítico de su época y precursor e Brasil de la prevision normativa del princípio del debido proceso legal y del juez natural, tiendo sido uno de los líderes del movimiento de 1831, que há culminado con la salida del monarca Don Pedro I. Su inteligencia y su pragmatismo político fue descrita por José Murilo de Carvalho, como un practicante de la realpolitik.

\section{PALABRAS CLAVE}

Política. Historia. Brasil Imperio. Monarquia. Realpolitik. Conservadurismo. Esclavitud. Derechos Fundamentales. Garantías. Debido Proceso Legal. Juez Natural.

\section{INTRODUÇÃO}

0 presente trabalho visa traçar um breve panorama da atuação política de Bernardo Pereira de Vasconcelos, um dos grandes estadistas do nascente império, e sua contribuição para o fortalecimento das instituições políticas de então e a promoção da defesa das liberdades públicas e garantias individuais.

Acerbo defensor dos ideais monárquicos, não poupava, com sua oratória parlamentar e mesmo na tribuna da imprensa escrita [colaborou, dentre outros, com os jornais Sentinela da Monarquia, O Brasileiro, O Sete de Abril, Correio da Tarde] críticas à figura do imperador, acreditando assim contribuir para o aperfeiçoamento das instituições do trono.

Chama a atenção de tantos quantos se debruçam sobre a vida e obra de Vasconcelos, sendo mesmo esta uma nota marcante de sua trajetória, a derivação política que sofreu no curso de sua ação parlamentar.

Do liberal moderado da legislatura de 1826, a primeira legislatura brasileira, para a adesão ao regresso conservador a partir de 1837, promovendo ainda a defesa aberta e sem recurso do regime de escravidão, concessões que faz aos imperativos da realpolitik.

A trajetória política desviante de Vasconcelos, tidas por muitos de seus contemporâneos por contraditória e incoerente, não deve empanar o brilho de sua atuação política e a contribuição à criação e cristalização de importantes instituições jurídico-políticas que perduram até a atualidade, a merecer o reconhecimento dos pósteros

\section{DO VENTRE DAS ELITES, NASCE UM LÍDER}

Mineiro de Ouro Preto, nascido nos idos de 1795, ilustre e abastada. 0 pai, português de nascimento, Bernardo Pereira de Vasconcelos provinha de família formou-se em Coimbra e praticou como advogado 
em Ouro Preto e juiz criminal no Rio de Janeiro. A mãe, brasileira Maria do Carmo Barradas, tinha pai e dois de seus irmãos eram igualmente formados em Coimbra.

Em sua formação e história de vida pública, Vasconcelos não fugiu aos padrões da elite dirigente de então. Bem ao revés, sua trajetória intelectual e política se enquadram com perfeição nos modelos da elite intelectual, social e política forjados naquele Brasil de fins do século XVIII e começo do século XIX - uma sociedade agrária, escravocrata, exportadora e machista, cujos pólos de concentração de população e vida econômica eram as províncias de Bahia, Pernambuco, São Paulo e Minas Gerais.

Graduado em direito na vetusta Universidade de Coimbra, formação acadêmica de resto obrigatória a tantos quantos pretendessem ascender na hierarquia administrativa e política do nascente estado imperial, é certo que da formação coimbrense Vasconcelos não parecia se orgulhar tanto a ponto de vir a afirmar, quando dos debates parlamentares que culminaram com a criação das faculdades de direito de Olinda e São Paulo, ter dito que o estudante, que saía da Universidade de Coimbra, devia, antes de tudo, desaprender o que lá se ensinava e abrir nova carreira de estudos. Teve breve passagem pela advocacia, ainda em Lisboa, e pela magistratura no Brasil. Escreveu na imprensa da época, sempre abordando temas de fundo político.

Foi deputado à Assembléia Geral de 1826 até 1837 e senador de 1838 até 1850, ano de sua morte. Foi ministro da fazenda durante a Regência Trina Permanente; ministro do império no período da regência de Pedro de Araújo Lima por duas vezes.

Sua consistente formação intelectual e esfuziante oratória parlamentar valeram-lhe a comparação a Benjamin Franklin e John Adams feita pelo reverendo irlandês Walsh, o autor de Notícias do Brasil que nos idos de 1828 privara do conhecimento de Vasconce- los. Já o historiador inglês John Armitage em sua História do Brasil elevou-lhe à categoria de Mirabeau do Brasil.

Ainda ecoa na história dos debates parlamentares brasileiros lembrança de Vasconcelos, sentado, incapaz de manter-se de pé em razão de doença degenerativa (possivelmente causada pela sífilis, um dos males incuráveis da época) que o acompanhou até o leito de morte, deitando sua oratória de fogo contra o outrora aliado Padre Diogo Antônio Feijó, um de seus alvos preferenciais.

Filho da elite, nascido em uma das províncias políticas e economicamente mais importantes do império - na verdade, o centro de exploração mineral do império quando da exportação de açúcar, associada à sua formação coimbrana e sua paulatina escalada na hierarquia do por imperial, fazem de Bernardo Pereira de Vasconcelos um dos arquétipos do que os professores Eul-Soo Pang e Ron L. Seckinger batizaram de mandarins do Brasil imperial, pertencentes a uma extração sócio-econômica a quem eram reservados os grandes postos da administração do império:

\footnotetext{
O sistema social do Brasil no século XIX, baseava-se na agricultura de exportação e na mineração, ambos baseados, em sua maior parte, no trabalho escravo. A classe dominante, ou elite social, foi composta principalmente pelos grupos ligados a economia de exportação - a aristocracia rural, os comerciantes envolvidos no comércio de importação e exportação, e os banqueiros estrangeiros e nacionais. Além desses grupos orientados para a exportação, a elite social incluiu os profissionais urbanos, oficiais militares e pessoas de destaque. Esta classe concentrava-se nas províncias gerais e subordinadas, mais intimamente envolvidos na economia de exportação, centradas nas províncias mais populosas: Bahia e Pernambuco, ao norte, e São Paulo, Minas Gerais e Rio de Janeiro centro, no sul. A elite social monopolizava as ocupações que foram consideradas "carreiras de cavalheiros." Os mais altos postos no governo relacionados a lei, diplomacia, administração pública, militar e Igreja foram profissões bens quistas, contudo a medicina e engenharia eram vocações progressivamente consideradas em patamar de significação similar. Desde que tais ocupações re-
} 
queriam um longo período de treinamento especializado e consequentemente, envolvendo altos custos, só os filhos de famílias ricas poderiam aspirar as carreiras da elite social. Um exame das certidões de nascimento dos diplomados (bacharéis) no começo do século XIX evidenciou a monopolização do ensino su- perior pelas oligarquias da economia de exportação. Dos 180 brasileiros que se formaram na Universidade de Coimbra entre 1800 e 1830, 49 deles (82,5 por cento) vieram das cinco províncias mais ricas e populosas. (PANG, 1972, p. 215-244, tradução nossa).

\section{A POLÍTICA COMO ELA É. CONTRADIÇÕES E RE- CUOS.}

Deputado geral à primeira legislatura imperial (1826), Bernardo Pereira de Vasconcelos, no curto espaço de apenas dois anos, logrou se afirmar como uma das personagens mais proeminentes do parlamento imperial.

Toda a insegurança cercava os trabalhos parlamentares da legislatura de 1826, afinal, eram ainda presentes os traumas da dissolução da assembléia constituinte de 12 de novembro de 1823, a qual não foi bastante para abrandar o inquieto espírito cívico do parlamentar, que então já marchava a passos céleres para se tornar um dos grandes vultos do império brasileiro.

Sua dedicação à vida pública, intensa participação nos trabalhos parlamentares e a retórica virulenta, a fazer tremer os adversários de sempre ou de ocasião, fizeram com que Vasconcelos ocupasse lugar de honra no panteão dos grandes homens do jovem império sul-americano.

O político e diplomata Joaquim Nabuco, que socolor de produzir a biografia de seu pai José Thomaz Nabuco de Araújo findou por dar à luz uma das mais importantes obras sobre as instituições políticas do Brasil, “Um Estadista do Império”, obra seminal e de referência para tantos quantos se voltam aos estudos das instituições políticas, registrava:

O jornalismo brasileiro tomara feição completamente nova com o aparecimento da Aurora Fluminense em
1827. O estilo da Aurora, como criação de uma só inteligência, é realmente um fenômeno notável. São os dois acontecimentos intelectuais da época: a pena de Evaristo da Veiga e a palavra de Evaristo Pereira de Vasconcelos. Uma e outra têm os mesmos característicos de solidez e de força que nenhum artifício pode substituir. Uma e outra são a ferramenta simples, mas poderosa, que esculpe o primeiro esboço do sistema parlamentar no Brasil. A figura de Vasconcelos, sobretudo, grava-se para sempre na imaginação de Nabuco. Do meio para o fim da sua carreira parlamentar este último falou sempre sentado, e os que o ouviram sabem que esta postura, em vez de privar o orador dos seus meios de ação sobre o auditório, aumentava a solenidade do gesto, a repercussão da palavra, a animação do discurso. Nesses dias, sempre de ansiedade para ele, o modelo que the vinha a lembrança era o busto do grande Vasconcelos, chumbado na paralisia na sua curul, mas dominado dela com um sarcasmo, uma pausa, um lampejo de olhar, a Câmara suspensa e maravilhada. (NABUCO, FAORO, MELLO, 1997, p. 42-43).

Homem de sua época, sujeito as contingências políticas, históricas e econômicas de então e sendo, sobretudo, um homem de ação disposto a arrostar os desafios que antepunham à consolidação do império, a atuação política de Vasconcelos não teve (fosse diferente talvez não se estivesse a escrever sobre ele) a linearidade tão cara aos que confundem coerência com miopia política quando não com a mais canhestra ranhetice.

De fato, Vasconcelos, que formou, nos começos de sua carreira política, nas fileiras dos liberais moderados e se é certo que foi um dos próceres do mo- 
vimento de sete de abril de 1831, que culminou com a deposição de Dom Pedro I, nada tinha de exaltado ou de radical, como de resto deixou entrever na sua Exposição dos Princípios do Ministério da Regência, em pronunciamento à Assembléia Geral feito em 23 de julho de 1831, quando já ministro da fazenda da regência trina:

\begin{abstract}
Agora, senhores, cumpre declarar como entendemos esta memorável revolução. A nação, abdicado o trono constitucional pelo primeiro príncipe que ela elegeu, nem teve intuito de subverter as instituições constitucionais e mudar a dinastia, nem o de consagrar a violência e proclamar a anarquia; usou sim do incontestável direito de resistência à opressão, e quis popularizar a monarquia, arredando-se dela os abusos e os erros que a haviam tornado pesada aos povos, a fim de reconciliá-la com os princípios da verdadeira liberdade. Firme nesta inteligência, o governo está firme também na repressão da violência e da sedição, executando e fazendo executar pontualmente as leis, e, quando estas não bastem, representando e propondo à Assembléia Geral as providências necessárias. A sedição é um crime, qualquer que seja o pretexto com que se revista; crime é também a violência, porque ela dá princípio à perturbação da ordem que só um governo fraco e as insuficiências das leis podem tolerar.(CARVALHO, 1999, p. 201).
\end{abstract}

A partir de 1934, com a aprovação do Ato Adicional, em que se emprestou uma maior autonomia às províncias do império, começa a marcha de Vasconcelos rumo ao regresso, até a ele abertamente e "com estrondo", ainda segundo Nabuco, em 1837.

É que com a maior autonomia conferida às províncias associada à ausência da figura imperial, elemento catalisador do elemento nacional e do sentimento ativista, outra não foi a conseqüência senão a eclosão de movimentos secessionistas como a Revolta dos Malês (1835) e a Sabinada (1837-1838), na Bahia, e a Guerra dos Farrapos (1835-1845) no Rio Grande do Sul, pondo em risco ao unidade territorial e a autoridade central do império nascente, num cenário em que a lembrança da guerra entre Brasil e Argentina (dezembro de 1825 a agosto de 1828), a importar perda territorial para o império ainda era muito nítida.

O seu receio de que o Ato Adicional de 1834 viesse a se tornar a Carta da Tirania é, talvez, o ponto de inflexão da guinada reacionária.

Outro aspecto a causar estupefação diz com a postura de Vasconcelos em face do elemento escravo. É que sobre os influxos liberais do movimento que culminou com a abdicação do Sete de Abril a Assembléia Geral, aprovou a 07 de Novembro de 1831, aquele que seria o primeiro golpe legislativo contra o tráfico negreiro.

A chamada Lei Feijó dispunha em seus primeiros artigos:

\footnotetext{
A Regência, em nome do Imperador o Senhor Dom Pedro Segundo, faz saber a todos os súditos do Império, que a Assembléia Geral decretou, e ela sancionou a Lei seguinte:

Art. $1^{\circ}$. Todos os escravos, que entrarem no território ou portos do Brasil, vindos de fora, ficam livres. Excetuam-se:

$1^{\circ}$. Os escravos matriculados no serviço de embarcações pertencentes a país, onde a escravidão é permitida, enquanto empregados no serviço das mesmas embarcações.

$2^{\circ}$. Os que fugirem do território, ou embarcação estrangeira, os quais serão entregues aos senhores que os reclamarem, e reexportados para fora do Brasil. Para os casos da exceção no. 1, na visita da entrada se lavrará termo do número de escravos, com as declarações necessárias para verificar a identidade dos mesmos, e fiscalizar-se na visita da saída se a embarcação leva aqueles, com que entrou. Os escravos, que forem achados depois da saída da embarcação, serão apreendidos, e retidos até serem reexportados.

Art. $2^{\circ}$. Os importadores de escravos no Brasil incorrerão na pena corporal do art. 179 do Código Criminal imposta aos que reduzem à escravidão pessoas livres, e na multa de $200 \$ 000$ por cabeça de cada um dos escravos importados, além de pagarem as despesas da reexportação para qualquer parte da África; reexportação, que o Governo fará efetiva com a maior possível brevidade, contratando as autoridades africanas para thes darem um asilo. Os infratores responderão cada um por si, e por todos. Art. $3^{\circ}$. São importadores:
} 
$1^{\circ}$. O Comandante, Mestre ou Contramestre.

$2^{\circ}$. O que cientemente deu, ou recebeu o frete, ou por qualquer outro título a embarcação destinada para o comércio de escravos.

$3^{\circ}$. Todos os interessados na negociação, e todos que cientemente forneceram fundos, ou por qualquer motivo deram ajuda, a favor, auxiliando o desembarque, ou consentindo-o nas suas terras.

$4^{\circ}$. Os que cientemente comprarem, como escravos, os que são declarados livres no art. 10.; estes porém só ficam obrigados subsidiariamente às despesas da reexportação, sujeitos contudo às outras penas. Art. $4^{\circ}$. Sendo apreendida fora dos portos do Brasil pelas forças Nacionais alguma embarcação fazendo o comércio de escravos, proceder-se-á segundo a disposição dos arts. $2^{\circ}$. e $3^{\circ}$. como se a apreensão fosse dentro do Império.

Arrefecidas as paixões provocadas pelo Sete de Abril, sob cujo calor a lei e para que se desse cumprimento a tratado firmado com a Inglaterra em 1826/1827 foi aprovada, evidenciou-se sua flagrante ineficácia diante do poderio dos traficantes negreiros, que prosseguiram com sua mercancia de almas sob os olhares complacentes das autoridades.

A lei passou para a história, mercê de sua gritante ineficácia, como "uma lei para inglês ver".

Ainda a assim, Vasconcelos, por sinceramente acreditar segundo alguns, que o fim da escravidão concorreria para a desagregação do tecido social e do território nacional, não dá tréguas e propõe em 1935 a revogação da lei em projeto de um só artigo:

Artigo Único: são revogados os primeiros seis artigos da lei de 7 de novembro de 1831, que declarou livres os africanos importados no Brasil

Em discurso proferido em 25 de Abril de 1843 o Senador Bernardo Pereira de Vasconcelos promove a defesa candente da escravidão, proferindo a frase célebre: "A África tem civilizado a América[...]" (CARVALHO, 1999, p. 268).

Parece assistir razão ao Professor José Murilo de Carvalho ao analisar a guinada conservadora de Vasconcelos:
Em 1843, Vasconcelos levou seu escravismo ao extremo, afirmando no Senado: 'É uma verdade: a África tem civilizado a América! Renuncio a todas as teorias [...] quero só o positivismo dos fatos.' Era a postura utilitária e amoral diante da política, de que Vasconcelos foi sempre acusado. Segundo seus inimigos, ele seria partidário do Benthan, só admitindo a moral dos interesses, o útil como único princípio diretor das ações.

Com toda a probabilidade, Vasconcelos começou por essa época a formular uma teoria do poder que ia além de desenhos jurídicos e institucionais. As turbulências da Regência lhe haviam sugerido que a ordem pública só poderia ser mantida se sustentada em pessoas que tivessem interesse material em sua manutenção. 0 que Feijó fizera pragmaticamente, como ministro da Justiça, armando os proprietários do Rio para lutar contra as revoltas militares, Vasconcelos erigiu em filosofia política. Em 1838, já de novo no ministério, essas idéias aparecem na teoria da 'classe conservadora'. Essa classe era composta 'dos capitalistas', dos negociantes, dos homens industriosos, dos que se dão com afinco às artes e ciências: daqueles que nas mudanças repentinas têm tudo a perder, nada a ganhar. Essa classe existiria em todos os países. Apareceria sempre que o progresso atingisse ritmo exagerado, como na fase jacobina da Revolução Francesa. Sua política era a do 'progresso ordenado', sem inércia, sem precipitação. No Brasil, ela fez pacificamente a Independência e evitou o 7 de abril, que a própria pátria se perdesse." (CARVALHO, 1999, p. 27).

A Vasconcelos, pela cambiante e nada retilínea trajetória de ação política, muito cobraram seus adversários coerência, inúmeras acusações de atuação contraditória e pouco afeita à própria palavra. A resposta saiu da tribuna parlamentar, em discurso proferido na Sessão 09 de agosto de 1837 da Câmara dos Deputados, em que o estadista parece sugerir que a política a de se reger por uma ética e padrões próprios, um tanto distintos daqueles que hão de reger as relações pessoais:

Vulgarmente se entende que tem caráter o homem que diz hoje o que disse há vinte anos, e o que dirá daqui a vinte anos. Entende-se que tem caráter o homem que abre o seu espírito à primeira idéia que se pousar nele, e que imediatamente o 
fecha, e deixa essa idéia tomar posse de seu espírito, e repele todas as modificações, todas as idéias, ainda que a experiência mostre que está em erro. Este é sem dúvida o pior dos estados. Homens tais, idéias tais só tem apreço no meio das facções, porque as facções vêm de princípios absurdos, servem a princípios absurdos, e não podem admitir modificação alguma no espírito do homem, sem que logo condenem este homem como trânsfuga, como desertor.

\section{DEFENSOR DAS LIBERDADES}

É consenso entre tantos quanto se debruçam sobre o legado político-jurídico de Vasconcelos ser inegável a sua contribuição, seja através da imprensa, seja através da atuação parlamentar, à construção da institucionalidade das instituições políticas do império e seu arcabouço legislativo, de que o projeto, tornado lei, do Código Criminal de 1830 é momento luminoso.

Entusiasta do Parlamento e das instituições da Monarquia constitucional inglesa, em inúmeras oportunidades se vê o parlamentar Vasconcelos na defesa de postulados e institutos que hoje estão cristalizados na consciência jurídica e democrática da nação.

Assim é que da tribuna da Assembléia Geral, no discurso que proferiu em 18 de junho de 1827, Vasconcelos se bate pela publicidade do processo:

Sr. Presidente, dos relatórios feitos no segredo da inquisição têm resultado as mais danosas e revoltantes injustiças. Dois tristíssimos exemplos, um da história mineira e o outro da portuguesa, servirão para justificar a importância que sou a esta matéria. É fama que os mineiros já pelo ano de 1790 conceberam o majestoso projeto de sacudir o juro europeu; homens os mais gentis nas letras e nas armas eram apontados como os autores desta gloriosa empresa, que não chegou a realizar-se. (CARVALHO, 1999, p. 50).
Em minha inteligência, porém, a firmeza de caráter tem outra acepção muito diversa. Chamarei logo de caráter aquele que rende culto aos princípios, só por amor dos princípios; e que, por conseqüência, quando a observação, o estudo, a experiência mostram que esses princípios devem ser modificados, que alguns deles devem ser renunciados em obséquio a verdade não hesita em sacrificar o erro, em lugar de persistir, mantendo opiniões errôneas. Chamo homem de caráter firme ao que, rendendo culto aos princípios assim entendidos no homem de Estado, quando modifica seus princípios, porque reconhece que eles não são verdadeiros no sentido em que os adotou." (CARVALHO, 1999, p. 238).

Na Carta aos Senhores Eleitores da Província de Minas Gerais, a primeira prestação de contas que um representante do povo faz aos seus eleitores de que se tem notícia no Brasil, datada de 30 de dezembro de 1827 e subscrita pelo “deputado da nação” Bernardo Pereira de Vasconcelos, advoga-se o devido processo legal e o princípio do juiz natural, lançando-se duras invectivas contra as comissões militares encarregadas do julgamento dos adversários de Dom Pedro I:

Com a extinção da Assembléia Constituinte expirou a liberdade da imprensa, que há poucos meses tinha nascido; e posto que garantissem a lei de 2 de outubro de 1823 e a Constituição da Monarquia, considerava-se arriscado o exercício do mais precioso direito do homem, isto é, o de comunicar por escrito seus pensamentos. Estes receios não eram destituídos de fundamentos, os ministros de então tinham perdido a confiança nacional por seus procedimentos ilegais. O periódico Tamoio devia ser acusado perante os jurados, mas mandou-se proceder à devassa para punir seus redatores, o célebre Barata foi julgado não pelos jurados, mas pela Relação, posto que não tivesse outros crimes, que abusos da liberdade de escrever; Chapuis foi deportado, e a prisão do redator do Independente da Bahia, ordenada pelo comandante militar contra as leis e a Constituição, não teve nem sequer formal desaprovação e em vez de ser punido foi o violador da Constituição e das leis despachado pelo pre- 
sidente da província de São Pedro do Sul.

Para punir algumas províncias foram suspensas as garantias constitucionais; criaram-se comissões militares contra as leis e a Constituição; e a liberdade e vida de milhares de famílias brasileiras foram postas à discrição de militares, bravos sim, e cobertos de glória marcial, mas alheios aos princípios de direito, e muito mais alheios à prática de julgar. Corra-se a esponja sobre os horrores cometidos por algumas dessas comissões menos por culpa de seus membros que por causa das instruções, ou para melhor dizer, pela natureza de tais tribunais militares.

Sim, senhores, as comissões militares são invento infernal. A história judiciária basta a convencer-nos de que o juiz conhecido antes do ato de julgar nem sempre se guia pelas leis ou pela razão natural; todos os peitos não são inacessíveis às paixões e à corrupção; e muito custa resistir aos embates do poder, empenhado nas decisões judiciais: mas o pior de todos os juízes é o escolhido pelo governo para sentenciar os que considera seus inimigos entre juízes assim escolhidos e assassinos, uma só diferença noto: e é que os primeiros matam com os aparatos judiciais, e sem estes os segundos. E como em um século de luzes, e no regime constitucional se ousa abreviar as fórmulas dos processos? Por que nos objetos insignificantes há o maior escrúpulo, recomenda-se cuidadosamente a observância das leis e das fórmulas, e nenhum escrúpulo há, nenhuma fórmula sequer, quando se ventila sobre a liberdade e a vida do cidadão? As fórmulas demoram algum tanto os processos, mas elas garantem a inocência: sem elas não pode haver justiça sobre a terra." (CARVALHO, 1999, p. 60).

Em mais de uma oportunidade bateu-se pela liberdade de imprensa, assunto hoje, como sempre, tão em voga,sem olvidar, contudo, da coibição de seus abusos, como se vê de outro trecho da "Carta aos Eleitores":

Um dos mais profícuos meios de disseminar a instrução pelos membros de uma sociedade é a liberdade de imprensa: a experiência das nações cultas demonstra com evidência esta verdade. Como poderia uma nação chegar ao conhecimento do bom ou mau procedimento de seus servidores, se não houvesse liberdade de o publicar pela imprensa? As informações raras vezes são exatas, quando os informantes não temem a pública censura. E como se obteria o conhecimento dos fatos, de que se pede informação, se a imprensa os não publicasse? Demais, é pela imprensa que se propagam os conhecimentos úteis. Eis a razão por que me pareceu que em um só capítulo devia tratar das leis sobre escolas públicas e das que respeitam os abusos da liberdade de imprensa. (CARVALHO, 1999, p. 116).
Ainda no mesmo documento Vasconcelos faz peroração atualíssima, que muito bem pode ser transplantada para discussão sobre a possibilidade do uso das forças armadas como força policial, debate ainda em curso no país.

Eu quereria que se declarasse, se for possível, que esta força nunca seria empregada contra os cidadãos, ou no interior do Império, senão nos dois únicos casos de invasão, ou rebelião; outros devem ser os meios para manter o sossego interno. Muito perigoso é acostumar o soldado a olhar o seu concidadão como inimigo: acostumem-se eles a repelir inimigos, e a respeitar os cidadãos. Napoleão mesmo, o maior déspota que tem havido, sempre fez diferença de tropa de gendarmeria da Guarda Nacional, e de tropa de primeira linha; ao menos pela sua instituição esta última era destinada a repelir invasões estrangeiras, e nunca para atacar os cidadãos, o que muitas vezes aconteceu o fato porque um déspota não conhece lei. Esta gendarmeria foi instituída para cuidar da segurança particular, para fazer as prisões de polícia, etc., e a Guarda Nacional para conservar o sossego público nos departamentos; bom seria que entre nós houvesse também alguma coisa semelhante: acostumem-se os nossos soldados a fazer face aos inimigos da liberdade pública; e muito nos convém que eles não se habituem (permita-se-me esta repetição) a voltar contra a nação as armas, que só devem ser empregadas contra os inimigos. (CARVALHO, 1999, p. 139).

Em discurso de 04 de julho de 1833, Vasconcelos defende a soberania dos vereditos do Tribunal do Júri Popular:

[...] a Relação durante a administração de d. Pedro I não se contentava em anular sentenças do júri, anulava e reformava-as; conhecia de fato e de direito: este procedimento apoiado pela administração de d. Pedro I é que subvertia e anulava a instituição do júri.

De que servia que na primeira instância fossem as sentenças proferidas pelos jurados, se em segunda instância, podiam ser revogadas, tanto pelo que respeita ao direito, como ao fato, pelos tribunais? Portanto enganou-se o nobre deputado, que disse que d. Pedro I não tinha feito ataques tamanhos à liberdade da imprensa, como a administração de 7 de abril, que aliás, como já mostrei, obrou legalmente, e ao menos tem muitas inteligências a seu favor; entretanto que o governo transato assinou verdadeiramente a liberdade da imprensa, acabando com a instituição do júri. (CAR- 
VALHO, 1999, p. 208).

É de Vasconcelos o projeto legislativo, apresentado em 04 de Maio de 1827, do que veio a ser o Código Criminal do Império, entrado em vigor em 08 de janeiro de 1831 por força de carta de lei.

O Código de 1830 representou significativo avanço na legislação penal de então, a primeira codificação criminal autenticamente nacional, lançando definitivamente na lata do lixo da história as ordenações filipinas, "misto de despotismo e beatice" na expressão do Conselheiro Batista Pereira.

Ilustrativamente transcrevem-se abaixo alguns poucos artigos do Código Criminal de 1830 em que se verifica a adoção de alguns princípios hoje consagrados em toda legislação criminal do ocidente, tais como o princípio da legalidade, anterioridade, proporcionalidade e cumulação das penas, bem assim sua imprescritibilidade, para que se fique apenas em alguns exemplos.

Art. 33. Nenhum crime será punido com penas, que não estejam estabelecidas nas leis, nem com mais, ou menos daquelas, que estiverem decretadas para punir o crime no grão máximo, médio, ou mínimo, salvo o caso, em que aos Juízos se permitir arbítrio.

Art. 61. Quando o réu for convencido de mais de um delito, impôr-se-lhe-hão as penas estabelecidas nas leis para cada um deles; e sofrerá as corpóreas, umas depois das outras, principiando, e seguindo da maior para a menor, com atenção ao grão de intensidade, e não ao tempo da duração.

Art. 65. As penas impostas aos réus não prescreverão em tempo algum.

A qualidade do Código de 1830 é de reconhecimento dos grandes penalistas da contemporaneidade. Colhe-se a opinião de Heleno Cláudio Fragoso:

Em 4 de maio de 1827, Bernardo Pereira de Vasconcelos apresentava à Câmara dos Deputados um projeto do código criminal, que serviu de base ao trabalho definitivo elaborado por uma comissão mista de deputados e senadores. Clemente José Pereira apresentou também, em 16 de maio de 1827, a primeira parte de um projeto, que, todavia, não chegou a ser considerado, dada a superioridade do primeiro trabalho. 0 Código Criminal transformou-se em lei a 16 de dezembro de 1830 e constituiu obra notável. Foi o primeiro CP autônomo da América Latina. Sofreu a influência das idéias que então dominavam na Europa, ou seja, dos princípios liberais do Iluminismo e do utilitarismo, e sobretudo da obra de Bentham, cujas idéias repercutem em várias soluções do Código. As influências legislativas mais importantes foram as do CP francês de 1810, e do Código napolitano de 1819, mas sem ser nosso código realmente obra independente, pode-se dizer que há nele originalidade em algumas disposições, a par de inegável superioridade técnica. Entre as características mais interessantes do Código estão: (a) a exclusão da pena de morte para os crimes políticos; (b) a imprescritibilidade das penas (inspirada no Código bávaro de 1813); (c) a reparação do dano causado pelo delito, estabelecida pelo próprio juiz criminal (disposição alterada por lei de 03.12.1841, que revogou o art. 31 do Código, transferindo tal indenização para o juízo cível); (d) o ter considerado agravante o ajuste prévio entre duas ou mais pessoas, para a prática do crime; (e) a responsabilidade sucessiva nos crimes de imprensa, antecipando-se à lei belga (20.07/1831), que divulgou o critério, conhecido como sistema belga. Roberto Lyra lembra ainda a previsão da circunstância atenuante da menoridade, desconhecida, até então, das legislações francesa e napolitana, e o arbítrio judicial no julgamento dos menores de 14 a 17 anos (art. $18, \S 10)$. A nosso ver, o mais significativo no Código Criminal foi a sua notável antecipação do moderno sistema dos dias-multa na pena patrimonial (cf. N. ${ }^{\circ}$ 294, infra). Este Código influenciou a legislação espanhola, ou seja, os Códigos de 1848 e 1870, que, por sua vez, serviram de modelos a muitos códigos da América Latina. Em 1832 foi promulgado o Código de Processo Criminal, que completou o sistema de nossa legislação penal." (FRAGOSO, 2003, p. 60).

\section{Idêntica é a opinião de Aníbal Bruno:}

Foi esse Código obra legislativa realmente honrosa para a cultura jurídica nacional, como expressão avançada do pensamento penalista no seu tempo; legislação liberal, baseada no princípio da utilidade pública, como havia de resultar naturalmente da influência de BENTHAM, que exerceu sobre o novo Código, como já fizera sentir no Código francês de 1810. Deste, aliás, e do napolitano, de 1819, é que mais se deixou influir o nosso Código do império. Mas, sem ser obra que se 
possa dizer em verdade independente, o Código de 1830 não se filiou estritamente nem a um nem a outro, tendo sabido mostrar-se original em mais de um ponto. É certo que impressionou penalistas estrangeiros, dizendo-se de alguns que aprenderam o português para lê-lo no próprio texto (HAUS, MITTERMAYER). Chegou mesmo a influir sobre uma corrente de legisla- ções penais. Nele se modelaram o Código espanhol de 1848 e os que lhe seguiram, de 1850 e 1870 , e, através deste, vários Códigos penais da América latina." (BRUNO, 2003, p. 103).

\section{CONCLUSÃO}

Procurou-se neste trabalho, em breves linhas, delinear os contornos da trajetória cívico-política de uma das mais grandiosas e controversas personalidades públicas dos primeiros vinte e cinco anos do Brasil imperial.

O seu legado de intervenções na vida política, de que o Código Criminal do Império (1830) talvez seja a obra palpável imorredoura, jaz gravado indelevelmente no corpo de leis e instituições políticas gestadas durante o primeiro reinado, o período regencial e os primeiros anos do segundo reinado, tendo amargado neste último período um certo afastamento da curul imperial, uma vez que a sua insurgência contra o golpe liberal da maioridade tenha feito com que, compreensivelmente, jamais fosse admitido ao círculo íntimo de Dom Pedro II.

São lapidares as palavras do ex-ministro do Superior Tribunal de Justiça, conterrâneo de nosso personagem, o jurista Adhemar Ferreira Maciel, em fecho ao seu artigo BERNARDO PEREIRA DE VASCONCELLOS, O LEGISLADOR:

\begin{abstract}
Seja como Deputado, Senador, Ministro e Conselheiro de Estado, ou mesmo Vice-Presidente da Província de Minas, Bernardo Pereira de Vasconcellos deixou marcas profundas em nossas instituições políticas e públicas que estavam nascendo. Como se deu com Mozart, poucas pessoas se foram despedir dele no cemitério do Catumbi. Não houve discursos, ainda que ali estivessem presentes alguns poucos parlamentares. 0 corpo deformado pela longa doença finalmente descansava. 0 gigante que fora Bernardo Pereira de Vasconcellos, aprisionado num corpo retorcido pela doença, ainda hoje, passados mais de 150 anos de sua morte, nos maravilha e nos põe a pensar se o parlamentarismo não teria sido melhor para o nosso sofrido Brasil[...] (MACIEL, 2005,p. 91).
\end{abstract}

\section{REFERÊNCIAS}

BRUNO, Aníbal. Direito Penal, parte geral, tomo I: introdução, norma penal, fato punível. Rio de Janeiro: Forense: 2003.

CARVALHO, José Murilo de. Bernardo Pereira de Vasconcelos. Rio de Janeiro: 1999.
ESCOSTEGUY FILHO, João Carlos. Construtor de certo império: Bernardo Pereira de Vasconcelos e a defesa da escravidão africana (1830-1840). Rio de Janeiro: 2008.

FRAGOSO, Heleno Cláudio. Lições de Direito Penal: parte geral. Rio de Janeiro: Forense, 2003. 
MACIEL, Adhemar Ferreira. Bernardo Pereira de Vasconcelos, o Legislador. In: Doutrina: Superior Tribunal de Justiça. Brasília: 2005.

NABUCO, Joaquim; FAORO, Raiymundo; MELLO, Evaldo Cabral de. Um estadista do império. Vol. I. Rio de Janeiro: 1997.
PANG, Eul-Soo e Seckinger, Ron L., The Mandarins Of Imperial Brazil, Comparative Studies in Society and History, Vol. 14, n. ${ }^{\circ}$ 2, março/1972, USA, Cambridge University Press, 1972, p. 215-244. 